\title{
Solar Chimney and Power Tower Techniques for Power Production in Nasiriya City
}

\author{
Rafid M. Hannun, ${ }^{*}$ Mohammed H. Khalaf,**Amel Hashim Husain*** \\ * College of Engineering, Thi-Qar University \\ ** Thi-Qar Directory of Electricity Distribution \\ **** College of Engineering, Mustansiriya University
}

\section{Abstract}

The solar chimney and power tower are two of modern promised energy which can develop by low losses, simplicity and high power.

In this paper, the solar chimney and fossil fuel power tower parameters are studied by using theoretical equations in computational fluid dynamics CFD that substituted in some computer programs such as MATLAP and FLUENT codes with additional related expressions. Five different models are used in this paper (Chimney height is: 12, 15, 20, 25, and 35 meter), (Diameter of collector base is: 5, 8, 10, 15, and 20 meter). The effect of inlet collector height, collector absorbability, solar radiation, ambient temperature, solar collector thickness and solar collector tilt angle are studied to find the other parameters and properties such as velocity distribution, power and efficiency of system. The erecting of power turbine is predicted by findings the velocity distribution between the base and chimney assembly. The numerical analysis was presented by using GAMBIT and FLUENT 6.3 to predict that high velocity at the expansion of chimney near the center of base - chimney bond position because of low density of air as a result to solar radiation flux (and burned gases cover collector in case of using the chimney for combustion of gases in oil refineries).. This position is very suitable for promoting and building the power turbine. The maximum power accumulated from these techniques is more than $\left(6.7 \times 10^{5}\right.$ Watt $)$ where the velocity is $(17.5 \mathrm{~m} / \mathrm{s})$. The study concluded that it is easy work to erect these chimney and power tower techniques closed to drilling and oil facilities in remote areas. So, all factors were studied to coincide with previous papers in this field.

Keywords: Solar Energy, Chimney, Power Generation, Turbine. 


\section{Introduction}

The solar chimney concept was proposed in 1970s by Schlaich and later in1980s studies were carried out witha $50 \mathrm{~kW}$ power prototype in Manzanares, Spain. The prototype had about 11000 $\mathrm{m}^{2}$ collector installed on a horizontal land area, $200 \mathrm{~m}$ height and 10 mdiameter chimney, and a $50 \mathrm{~kW}$ nominal power turbine ${ }^{[1]}$. The three important parts of a solar chimney power plant are the collector system, the chimney and the air turbine as shown in Fig. (1). Ambient air enters the collector system from the periphery of the collector and heated mainly by convection along the hot ground. It enters at the bottom of the chimney due to pressure potential generated by the difference of density between the warm air and ambient air.

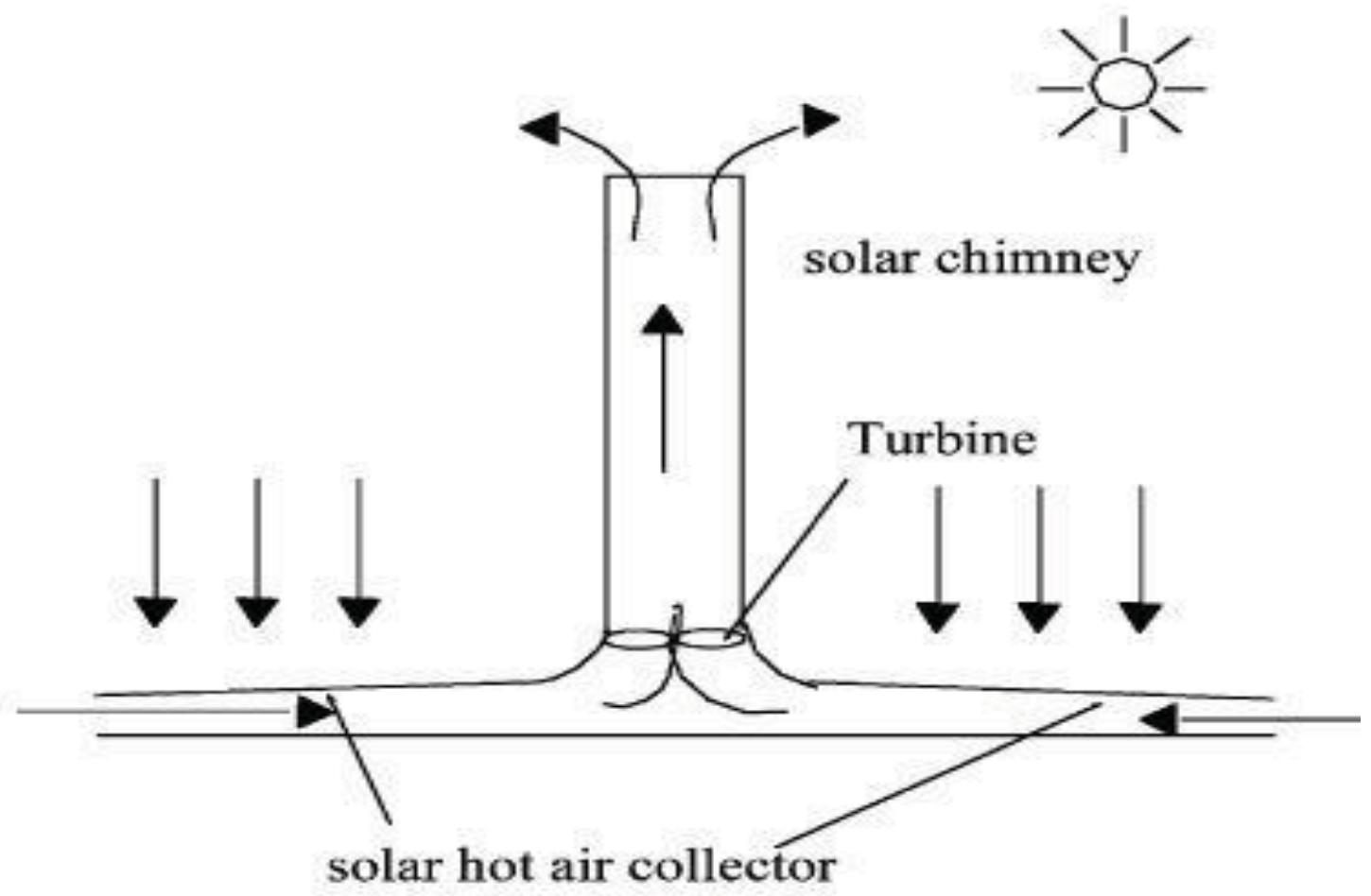

Fig.(1) Schematic diagram of the solar chimney

Schlaich(1995) was credited as being the first to propose solar chimney as a means to harness energy from the sun[2].Pasumarthi and Sherif (1998) reported that increase of tower height resulted in higher velocity and mass flow rate; and when the insulation was fixed, an increase in the mass flow rate was accompanied by a lower air temperature at the collector 
outlet $^{[3]}$. Chitsomboon (2001) found that efficiency of the plant was invariant with respect to the insulation level and size[4].Dai et al. (2003)demonstrated that the power output increased nonlinearly with the size of the plant, rapidly when the size was small and at a slower rate when the size was larger[5]. Schlaich et al. (2005) proposed that the overall efficiency was influenced only by the tower height [6]. More recently, Tingzhen et al. (2006) reported that efficiency should also be affected by solar radiation and collector radius [7].Xu et al. (2011), performed a numerical simulation of a solar chimney with an energy storage layer similar to the Spanish prototype ${ }^{[8]}$.Patel et al. (2014), introduced theoretical study of the flow characteristics inside the solar chimney power plant by using a computational fluid dynamics (CFD) software (ANSYSCFX) [9].

The aim of this study is to analyze the power chimney system by using the solar radiation equations applied by MATLAP and FLUENT program codes at Nasiriya city, so, to study the feasibility of turbine situation erection at the canopy -chimney section of the system base and to use this system closed to drilling and oil facilities in remote areas

\section{Theoretical analysis}

The convective heat transfer coefficient between the outer collector plate $\left(\mathrm{W} / \mathrm{m}^{2} . \mathrm{K}\right)$ and the surrounding (outside air) can be found as [10]:

$$
\mathrm{h}_{\mathrm{w}}=5.47+3.95 \times \mathrm{V}_{\mathrm{w}}
$$

The pressure developed in chimney is calculated from equation [11]:

$$
\Delta \mathrm{P}_{\text {ch. }}=\left(\rho_{\mathrm{a}}-\rho_{\mathrm{e} . \mathrm{c}}\right) \mathrm{g} \mathrm{H}_{\mathrm{ch}}
$$

The velocity of air inlet to chimney is calculated by ${ }^{[12]}$ :

$$
\mathrm{U}=\sqrt{\frac{2 \times \Delta \mathrm{P}_{\mathrm{ch}}}{\rho_{\mathrm{e} . \mathrm{c}}}}
$$

The mass flow rate of air inlet chimney is calculated from equation [13]:

$$
\mathrm{m}^{\mathrm{o}}{ }_{\mathrm{ch} .}=\rho_{\mathrm{e} . \mathrm{c}} \mathrm{UA}_{\mathrm{ch}} .
$$

The power output of solar chimney power plant is calculated from equation $\left.{ }^{[14}\right]$ :

$$
\mathrm{P}=\Delta \mathrm{P}_{\text {ch. }} . \mathrm{UA}_{\mathrm{c}}
$$

The efficiency of solar chimney plant is calculated as:

$\eta_{\text {ch. }}=\frac{\text { output power }}{\text { input power }}=\frac{\Delta \mathrm{P}_{\text {ch. }} \mathrm{UA}_{\mathrm{c}}}{\mathrm{I} \mathrm{A}_{\mathrm{c}}}$ 


\section{2- Results and Discussion}

In this study, five models are used as demonstrated in table (1) below by changing the chimney height with canopy diameter. The choice of these values depend on some practical and theoretical models that used by researchers before. All equations above are programmed by using MATLAP program code.

The paper results include six cases depending on many parameters such as: ambient temperature, total solar radiation, and wind speed, height of collector and transmittance of collector for solar energy.

Case (1) : For $\mathrm{T}_{\mathrm{amb}}=45 \mathrm{C}^{\mathrm{o}}, \mathrm{I}=1000 \mathrm{~W} / \mathrm{m}^{2}, \mathrm{~V}_{\text {wind }}=2 \mathrm{~m} / \mathrm{s}$, Height of collector $=1 \mathrm{~m}, \tau=0.85$. Fig. (2) shows the power which can be produced by system at different vent heights of collector (glass transparent media canopy).It is logical to see the maximum power is produced by larger diameter of base and chimney height (Model V) where more solar energy is absorbed by solar collector and create high pressure gradient between the base and higher point of chimney because of the height. It is shown that the maximum power is produced when the collector height is $0.2 \mathrm{~m}$ and gradually decreases to the minimum value at maximum height of collector. This give interpretation that when the canopy height increases the power decreases because of low heat storage under the canopy while the hot air is not accumulated under this place. Therefore, the power is proportional to velocity value of air inside the system passing from the outer edge of collector through chimney since the solar energy absorbed by air under the collector increases the velocity of warm air as a result to decrease air density inside as shown in fig (3). The same trend is shown for system efficiency as in fig (4). When the power and velocity are high then the efficiency is high and vice versa for all models. The maximum power, velocity and efficiency are produced for model $\mathrm{V}$ because of wider solar collector area and larger chimney height, and the minimum for model I.

Case (2): For $\mathrm{T}_{\mathrm{amb}}=45^{\circ} \mathrm{C}, \mathrm{I}=1000 \mathrm{~W} / \mathrm{m}^{2}, \mathrm{~V}_{\text {wind }}=2 \mathrm{~m} / \mathrm{s}$, Height of collector $=1 \mathrm{~m}, \mathrm{~h}_{\text {inlet to coll. }}=0.1$ m. i.e. the same parameters in case (1) but made the height of collector is constant $(1 \mathrm{~m})$ and the vent height of collector inlet is 0.1 . It is shown in Fig. (5) that the power produced by the chimney system increases as the collector absorptivity increases from since it is a function to solar energy absorbed by the collector which increases the movement of air from inlet to outlet of system. The maximum values are obtained by model $\mathrm{V}$, which is $2.5^{*} 10^{5} \mathrm{~W}$ to $8.5^{*} 10^{5} \mathrm{~W}$ for 
this model when the absorptivity increases from 0.5 to 0.95 respectively. The velocity increases from 12 to 19.5m/s as shown in Fig. (6) while the efficiency of system, shown in Fig. (7). states the maximum values for model $\mathrm{V}$ is between $0.8 \%-2.7 \%$.

Case (3): For $\mathrm{T}_{\mathrm{amb}}=45^{\circ} \mathrm{C}, \mathrm{V}_{\text {wind }}=2 \mathrm{~m} / \mathrm{s}$, Height of collector $=1 \mathrm{~m}, \mathrm{~h}_{\text {inlet to coll. }}=0.1 \mathrm{~m}, \tau=0.85$. It is the same as previous case but with constant transmittance to solar energy. Figure (8) Shows increase the output power of system with increase the solar radiation up to $1000 \mathrm{~W} / \mathrm{m}^{2}$. The velocity and efficiency shown in Figs. (9 and 10) respectively show the same prediction of proportional increase with solar intensity supplied to the collector.

Case (4):For $\mathrm{V}_{\text {wind }}=2 \mathrm{~m} / \mathrm{s}$, Height of collector $=1 \mathrm{~m}, \mathrm{~h}_{\text {inlet to coll. }}=0.1 \mathrm{~m}, \mathrm{I}=1000 \mathrm{~W} / \mathrm{m}^{2}, \tau=0.85$. This case is the same as case (3) but with changing the ambient temperature $(20-50)^{\circ} \mathrm{C}$ as shown in Figures (11- 13). Figure (11) Presents the power of $(5.9-6.9) * 10^{5} \mathrm{~W}$ for the model V but the minimum values are for model I $(0.06-0.1) * 10^{5} \mathrm{~W}$. So, the air velocity from the simulated prototype is (16.4- 18) $\mathrm{m} / \mathrm{s}$ as maximum for model $\mathrm{V}$ and minimum for model I (9.6- 10.6) $\mathrm{m} / \mathrm{s}$ as displayed by Fig. (12). Therefore, the efficiency follow the same prediction of power and velocity to be (1.9- 2.2)\% for model V and (0.39- 0.46)\%for I that exhibited in Figure (13).

The main previous parameters of this paper decreases by increase of collector cover thickness where the solar energy passes throughout its transparent media particles (glass) as shown in Figs. $(14,15$, and 16) for power, velocity and efficiency respectively when the thickness (0.0020.02) $\mathrm{m}$ for Case (5): For $\mathrm{T}_{\mathrm{amb}}=45 \mathrm{C}^{\mathrm{o}}, \mathrm{V}_{\text {wind }}=2 \mathrm{~m} / \mathrm{s}$, Height of collector $=1 \mathrm{~m}, \mathrm{~h}_{\text {inlet to coll. }}=0.1 \mathrm{~m}$, $\mathrm{I}=1000 \mathrm{~W} / \mathrm{m}^{2}$. The proportional decrease because of the impedance as a result to long distance (thickness) that the solar energy passes through it (absorption, reflection and refraction).

The surface tilt angle of transparent media of canopy that covers the solar chimney base affects the solar energy transmitted to base storage surface of power chimney system with the same reason of thickness mentioned in above paragraph that the arrays pass throughout inclined way depend the tilt angle of erection to system as presented by Case (6) : For $\mathrm{T}_{\mathrm{amb}}=45^{\circ} \mathrm{C}, \mathrm{V}_{\text {wind }}=2$ $\mathrm{m} / \mathrm{s}$, Height of collector $=1 \mathrm{~m}, \mathrm{~h}_{\text {inlet to coll. }}=0.1 \mathrm{~m}$, for $14 / 3$, at $12 \mathrm{PM}, \tau=0.85$. The Figure (1719) indicate that the optimum values of power, velocity and efficiency happen when the tilt angle is about $30^{\circ}-34^{\circ}$ since the effect of position (declination, latitude, altitude, zenith, azimuth, meridian and other solar angles) that changed from day to day and from season to another.

The validation of present work is done by the comparison with previous published and depended papers with the same or closed conditions. The efficiency of both studies compared with the same ambient temperature conditions is shown in figure (20). The domain of this study is 
0.029\%- 0.15\% for Model I mentioned above but for Sakir et. al [15] was 0.02\%- 0.1\% whose used the plant covering approximately 16.4 sq. meter area has a polythene cover as the collector instead of glass for reducing the cost. The base is tar covered concrete. The tower is made of PVC and approximately 3.05 meters high. These comparison values give an agreement with results prediction which made this study to be depended.

In addition to the previous validity, the results of this paper were compared by domain analysis by using GAMBIT and FLUENT codes. Figure (21) indicates the velocity magnitude throughout the solar chimney by using $800 \mathrm{~W} / \mathrm{m}^{2}$ solar flux with model of $100 \mathrm{~m}$ height of chimney and 2.5 $\mathrm{m}$ its radius and the collector of $60 \mathrm{~m}$ radius and $2 \mathrm{~m}$ height are used to be more suitable for practical utilization. The maximum velocity about $38 \mathrm{~m} / \mathrm{s}$ which is reasonable value in comparison with the dimensions of height of chimney and collector diameter. Also, the radiation intensity affects the velocity of air inside the chimney as shown in figure (22) for (800, 600, 400 and 200) $\mathrm{W} / \mathrm{m}^{2}$ that proportional to velocity values.

\section{Conclusions}

From the presentation of the results for this paper, it can be conclude the following:

1. The solar power chimney can be used as quantity production at the fields closed to Nasiriya city by increase the volume.

2. The oildrilling and facilities remote areas can utilize these power chimneys since their dependence on the sun.

3. The fossil fuel can be used to operate the turbines in such chimney technique.

4. All factors were studied to coincide with previous papers in this field and different computer programs. 
Table(1) five models for different parameters.

\begin{tabular}{|c|c|c|}
\hline & Height of chimney(m) & $\begin{array}{c}\text { Diameterof } \\
\text { collector(m) }\end{array}$ \\
\hline Model I & 12 & 5 \\
\hline Model II & 15 & 8 \\
\hline Model III & 20 & 10 \\
\hline Model IV & 25 & 15 \\
\hline Model V & 35 & 20 \\
\hline
\end{tabular}

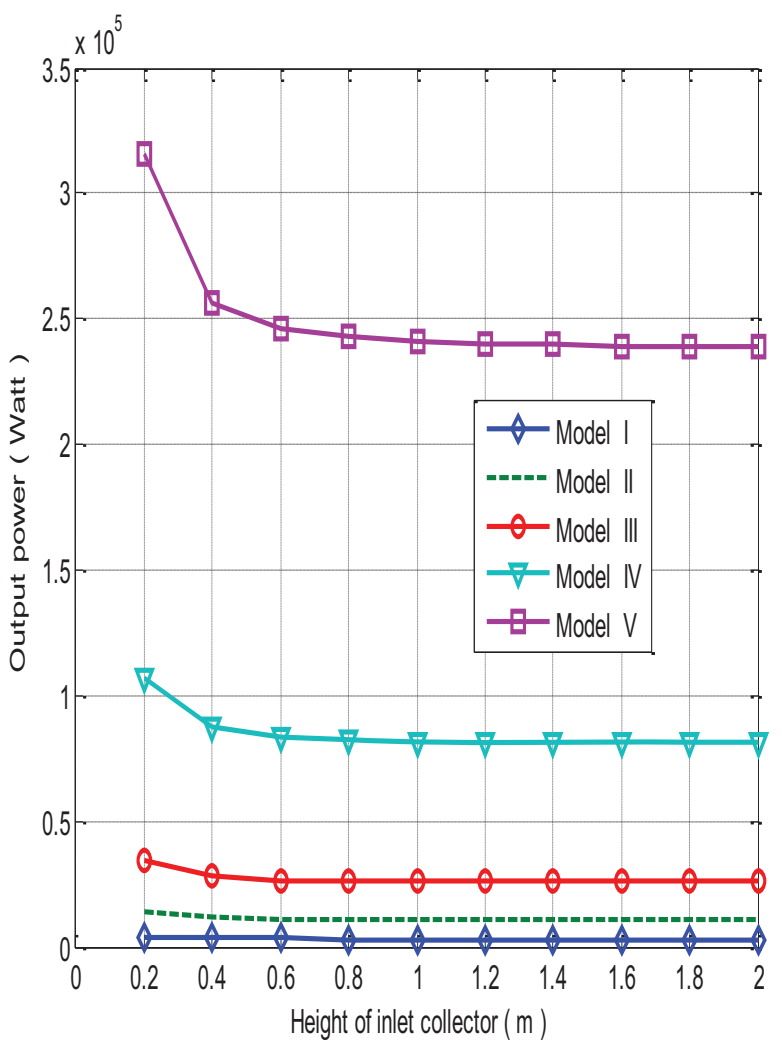

Fig. (2) Output power of system of

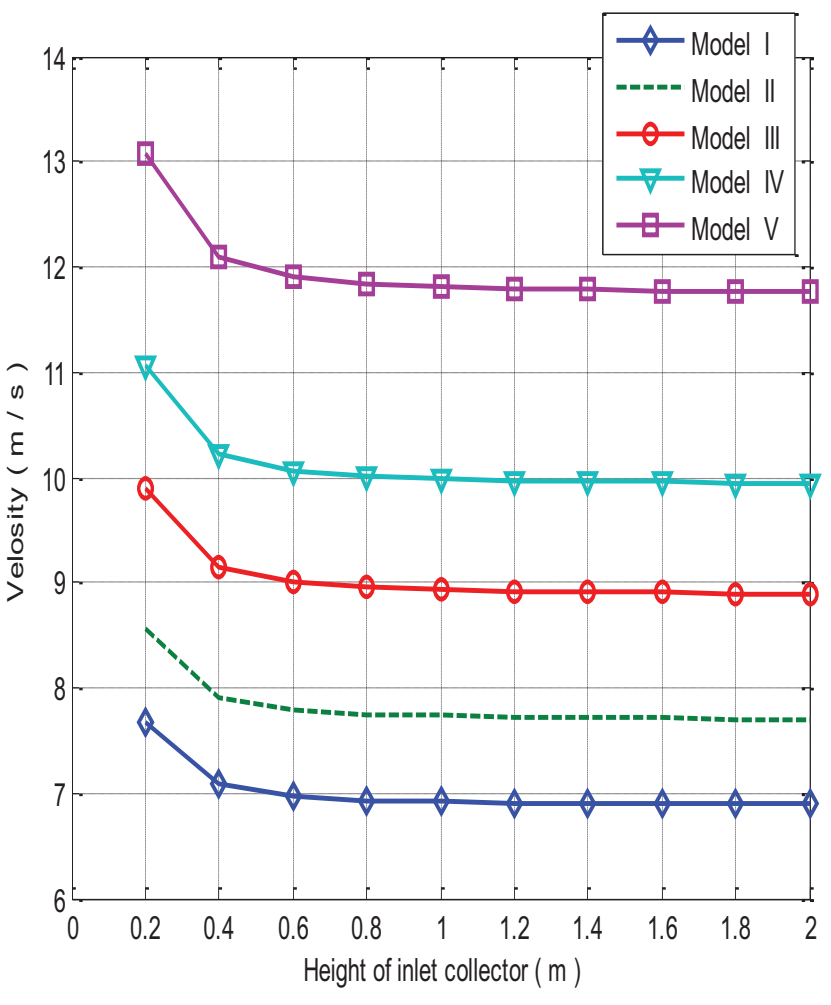

Fig. (3) Output velocity of system of case 


\section{No.18}

Journal of Petroleum Research \& Studies

(JPR\&S)

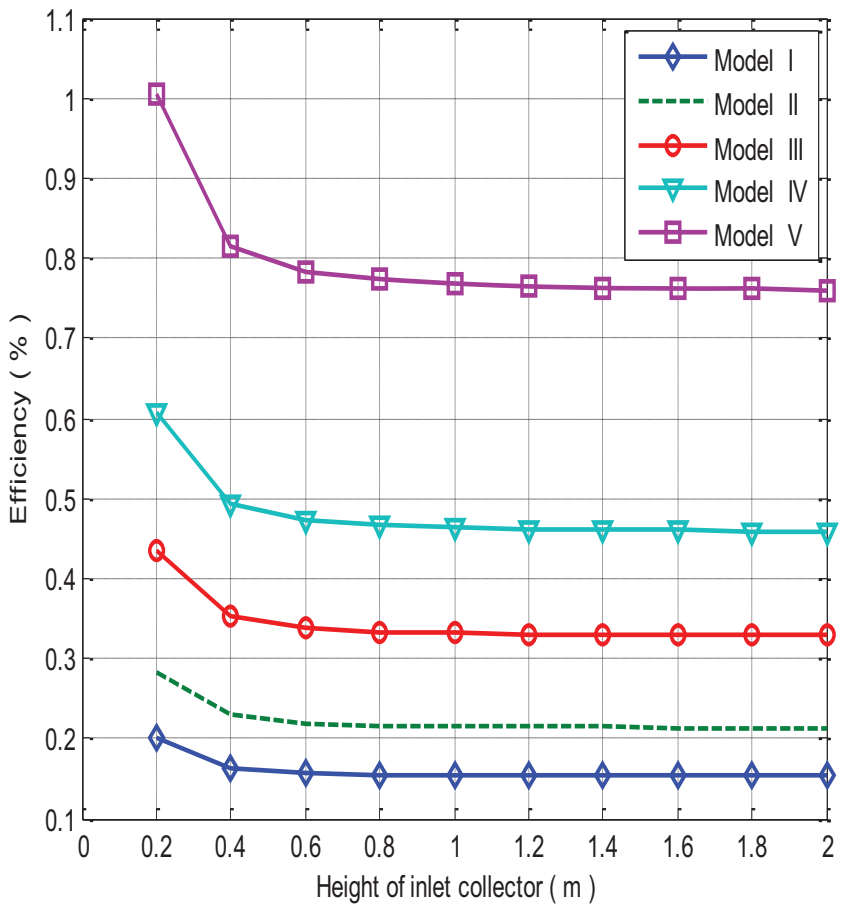

Fig. (4) Efficiency of system of case

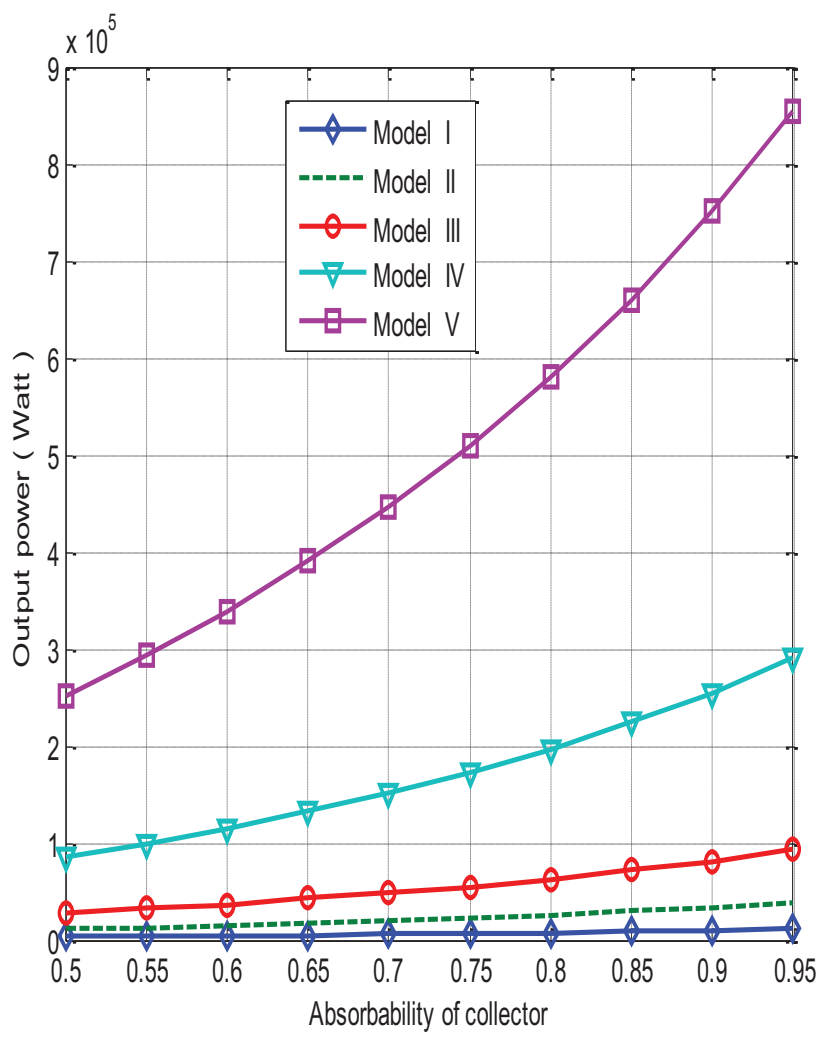

Fig.(6) Output power of system of

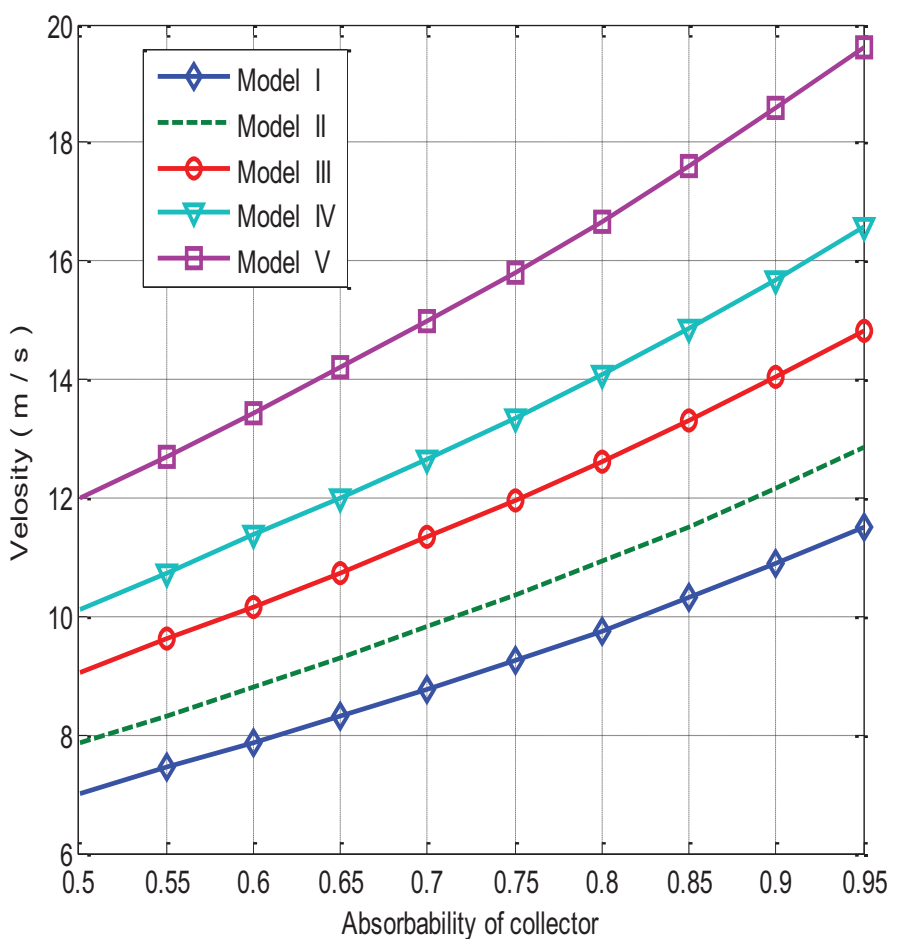

Fig. (5) Output velocity of system of case 2

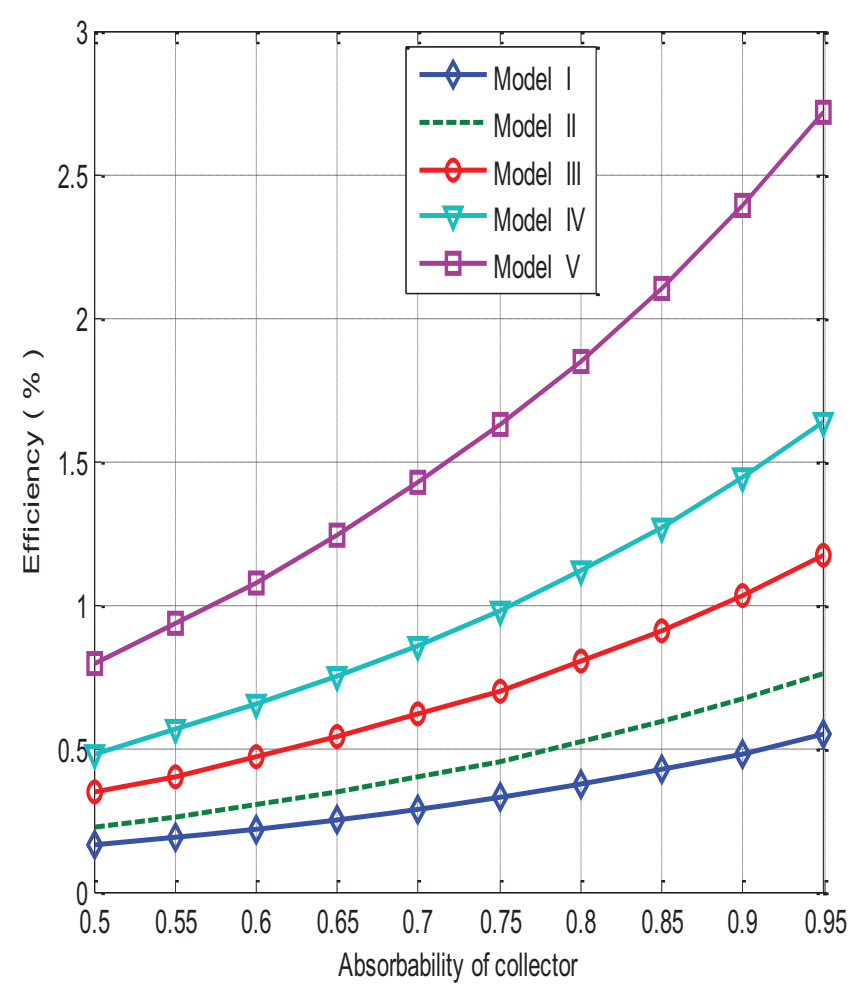

Fig. (7) Efficiency of system of case 2 


\section{No.18 Journal of Petroleum Research \& Studies}

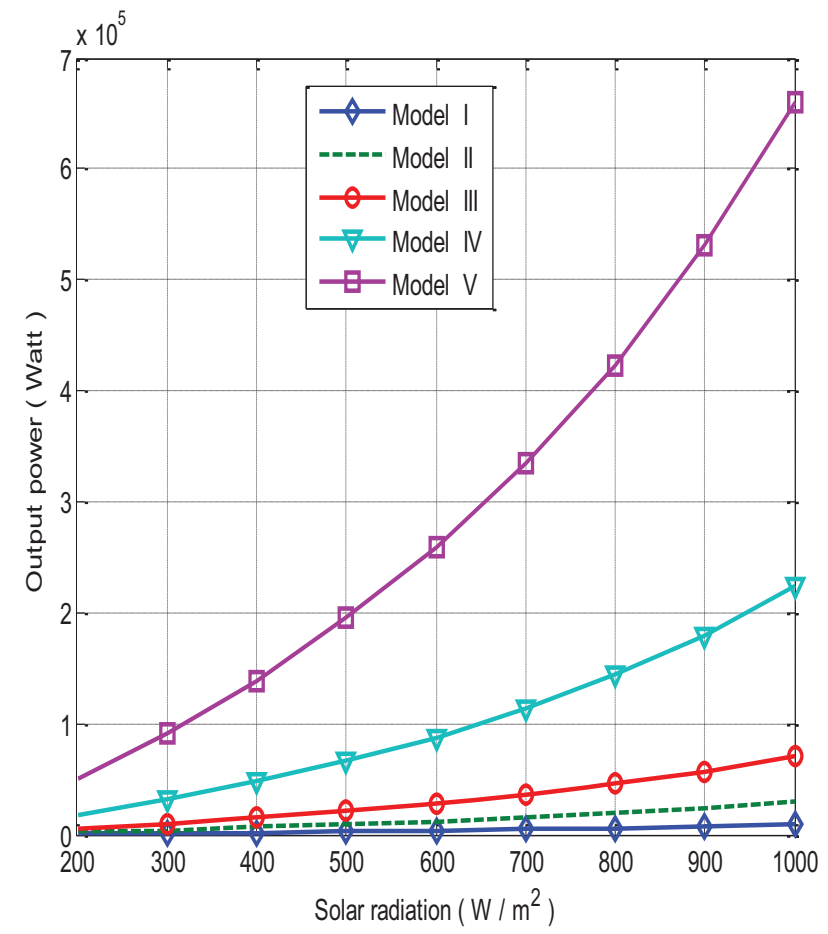

Fig. (8) Output power of system of

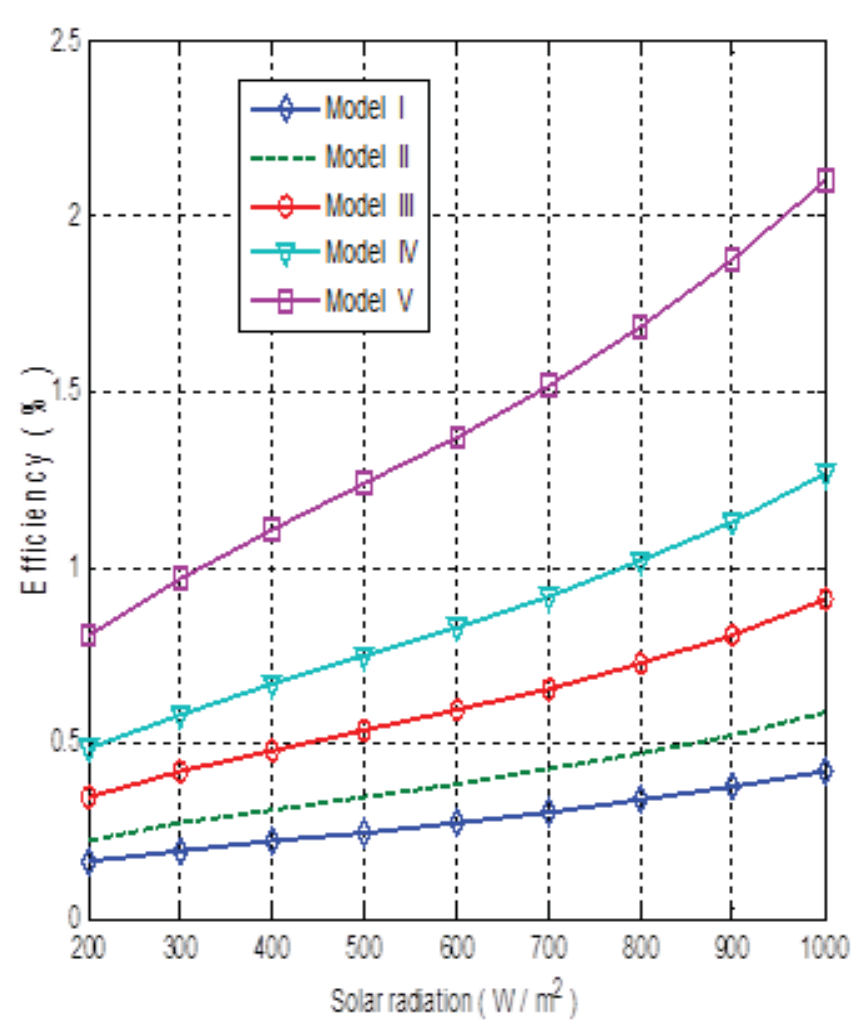

Fig.(10) Efficiency of system of case 3

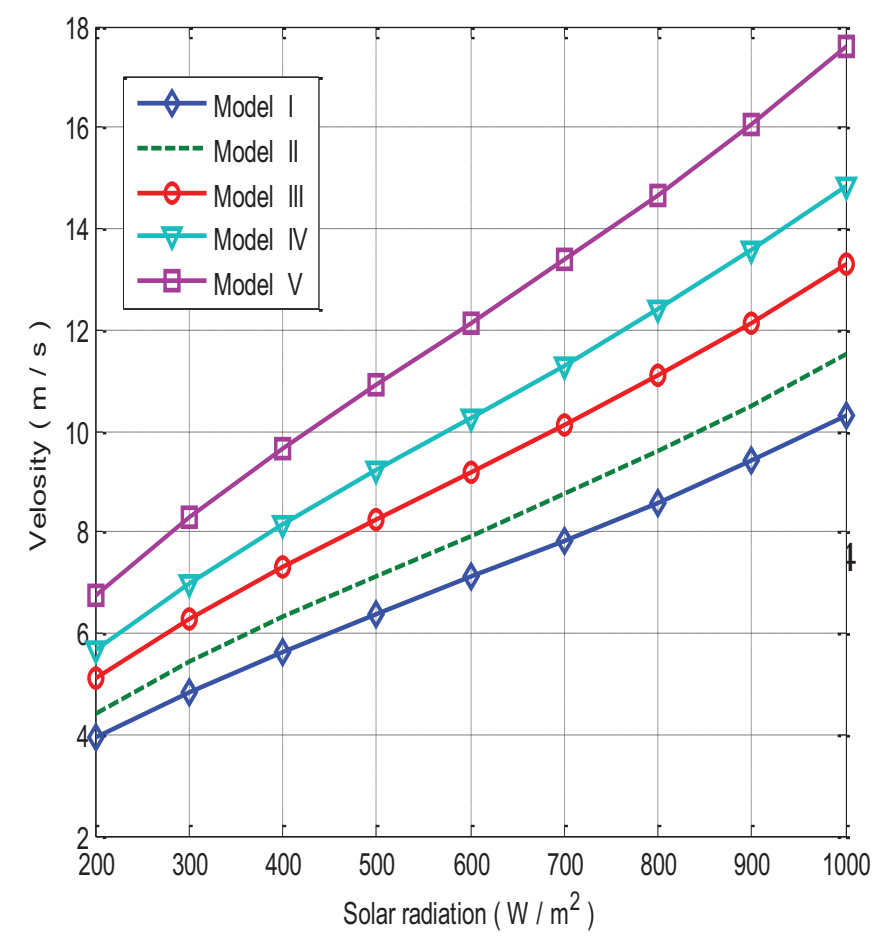

Fig. (9) Output velocity of system of

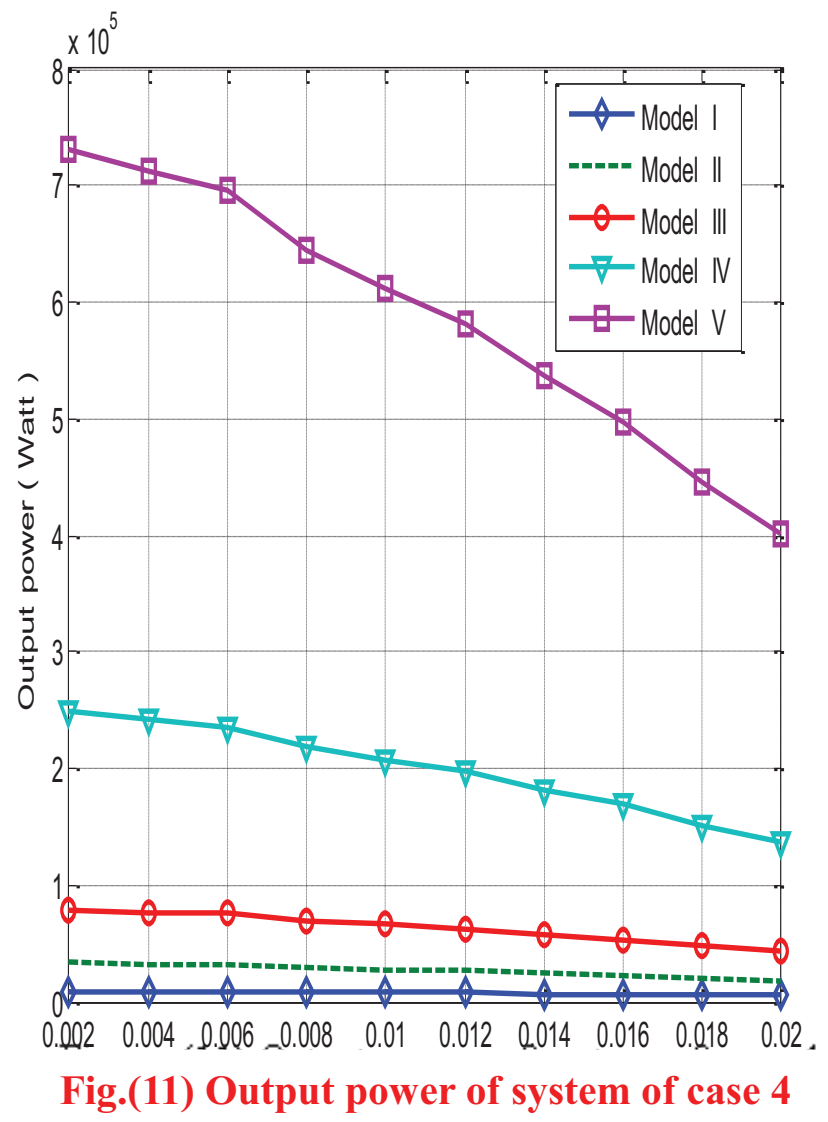




\section{No.18}
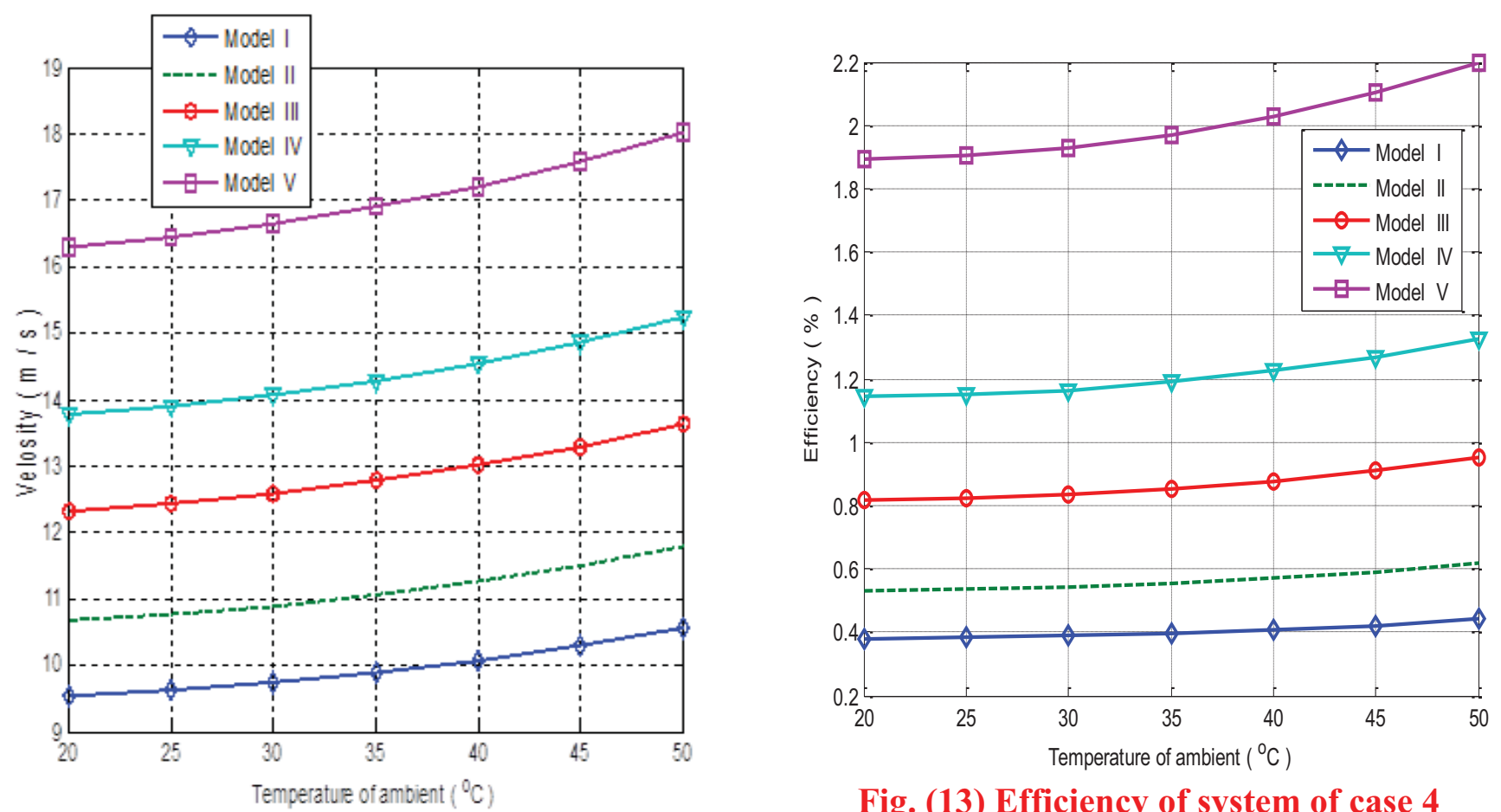

Fig. (13) Efficiencv of svstem of case 4

Fig.(12) Output velocity of system of case 4

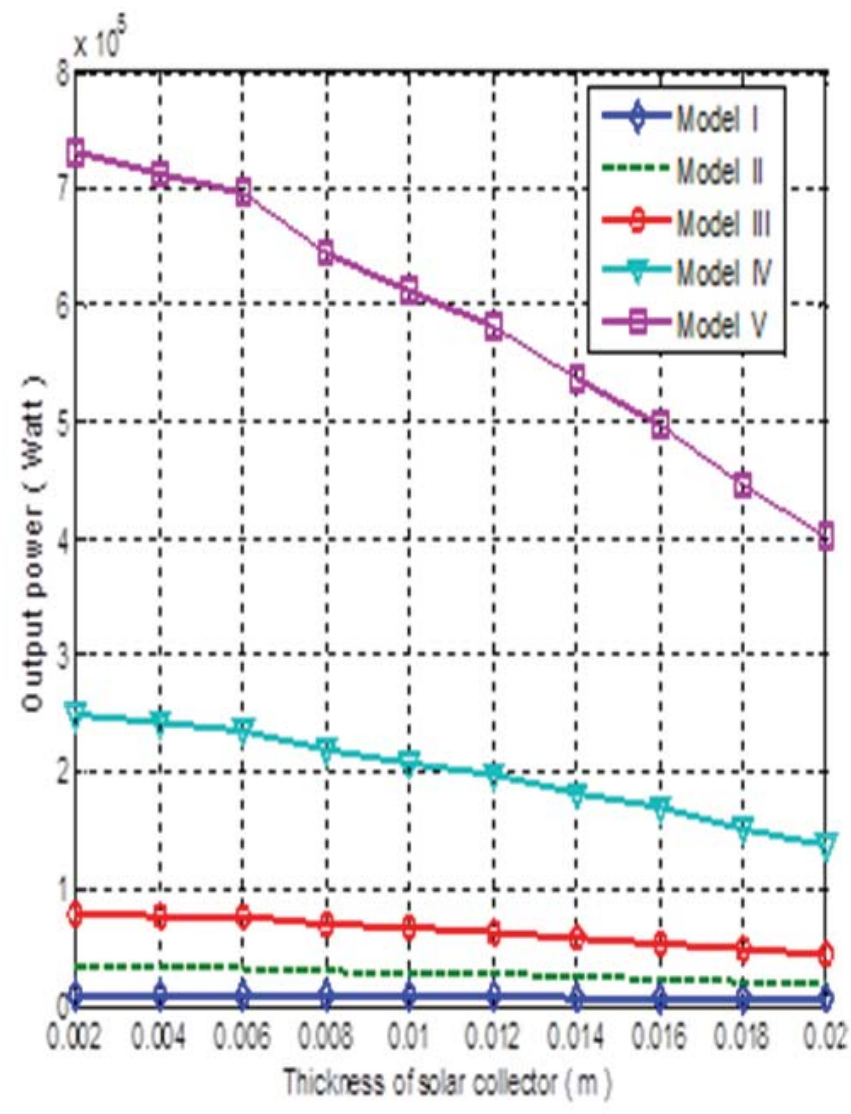

Fig.(14) Output power of system of case 5

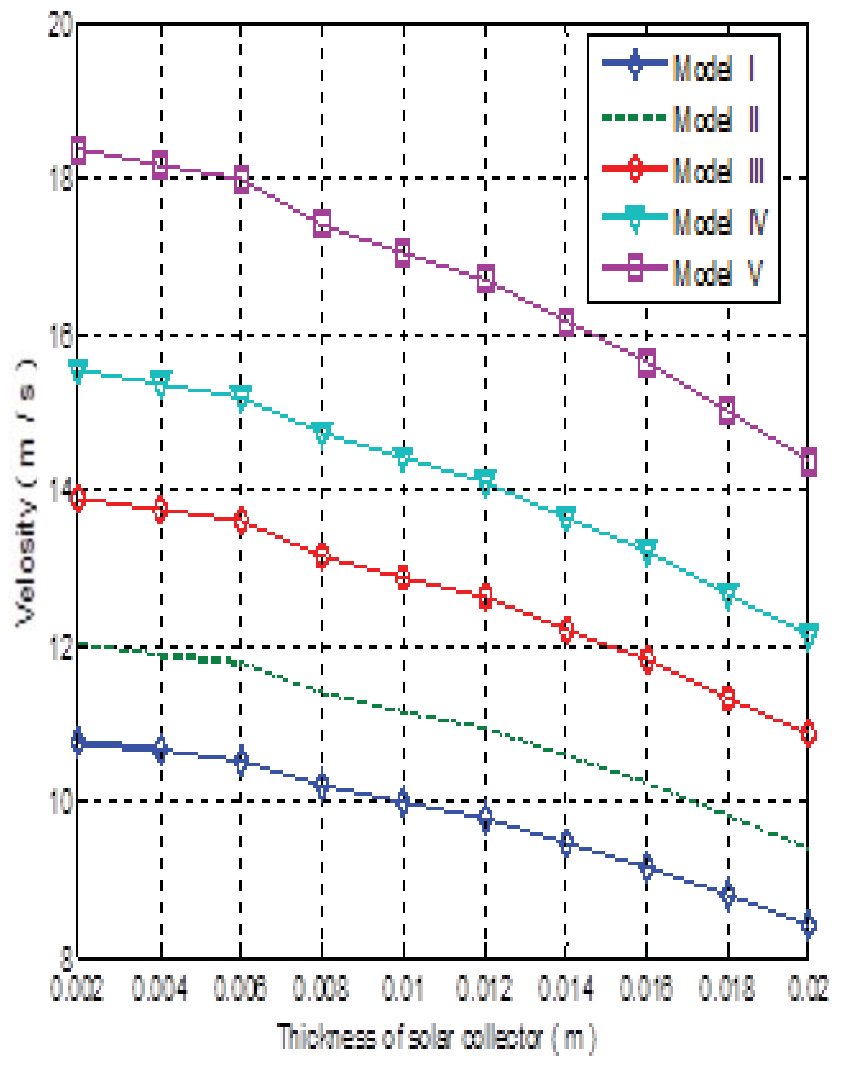

Fig.(15) Output velocity of system of case 5 


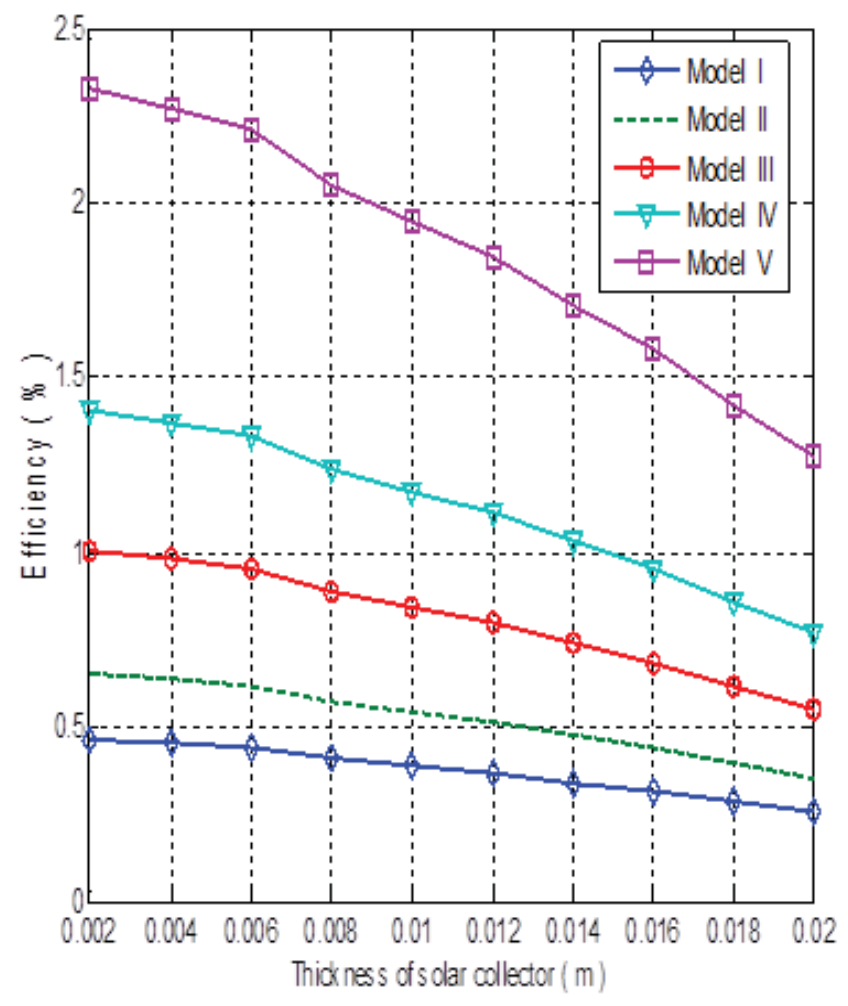

Fig.(16) Efficiency of system of case 5

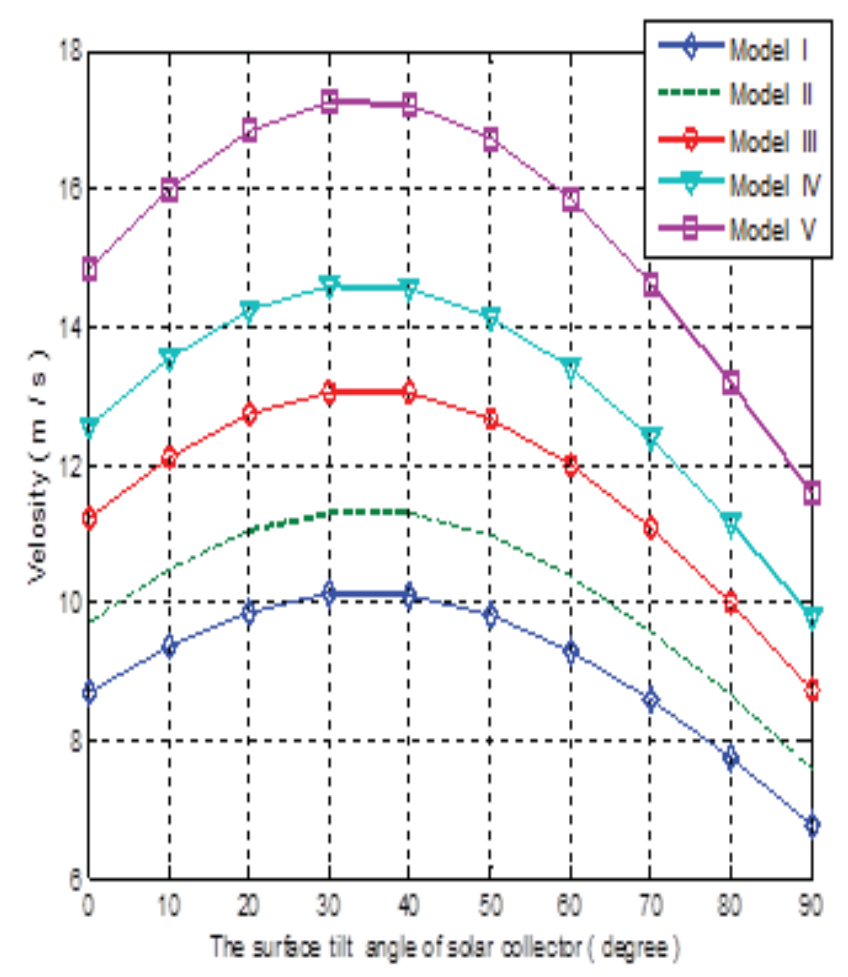

Fig.(18) Output velocity of system of case 6

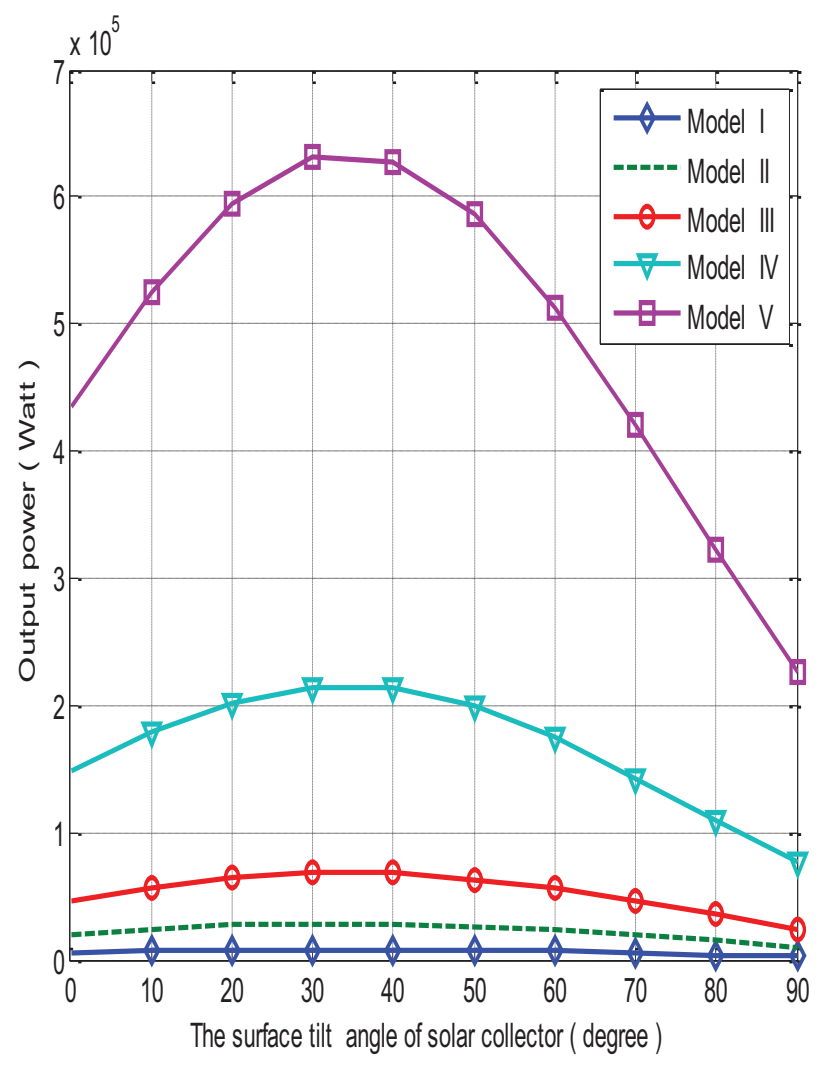

Fig. (17) Output power of system of case 6

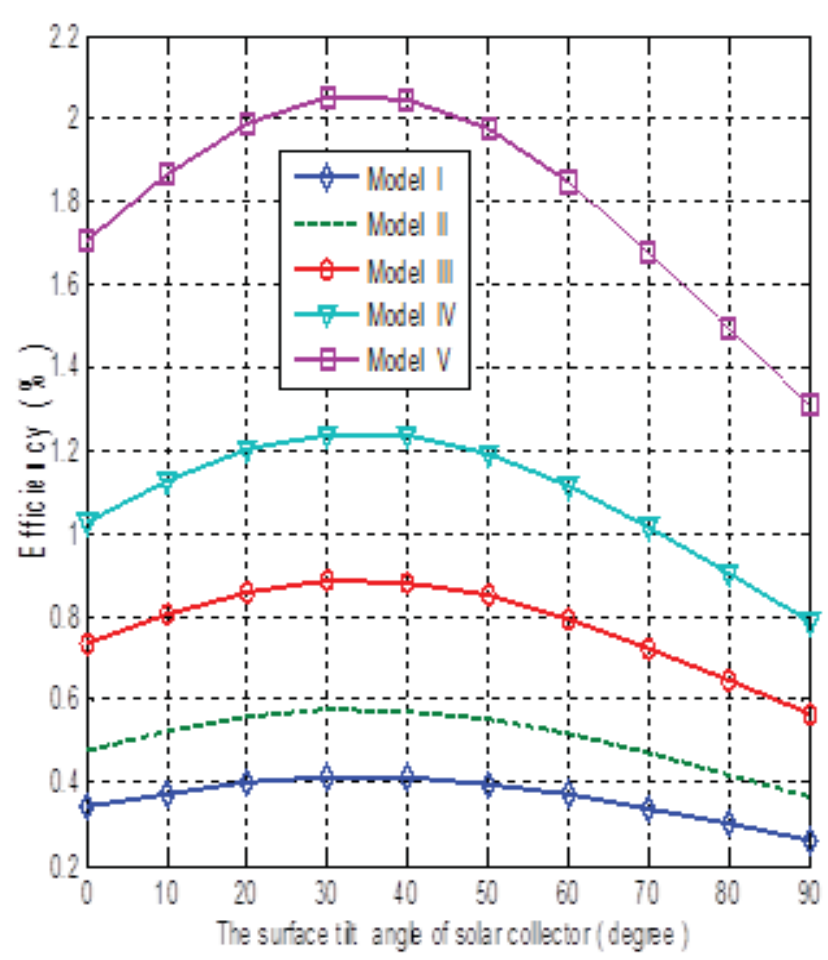

Figure (19) Efficiency of svstem of case 6 


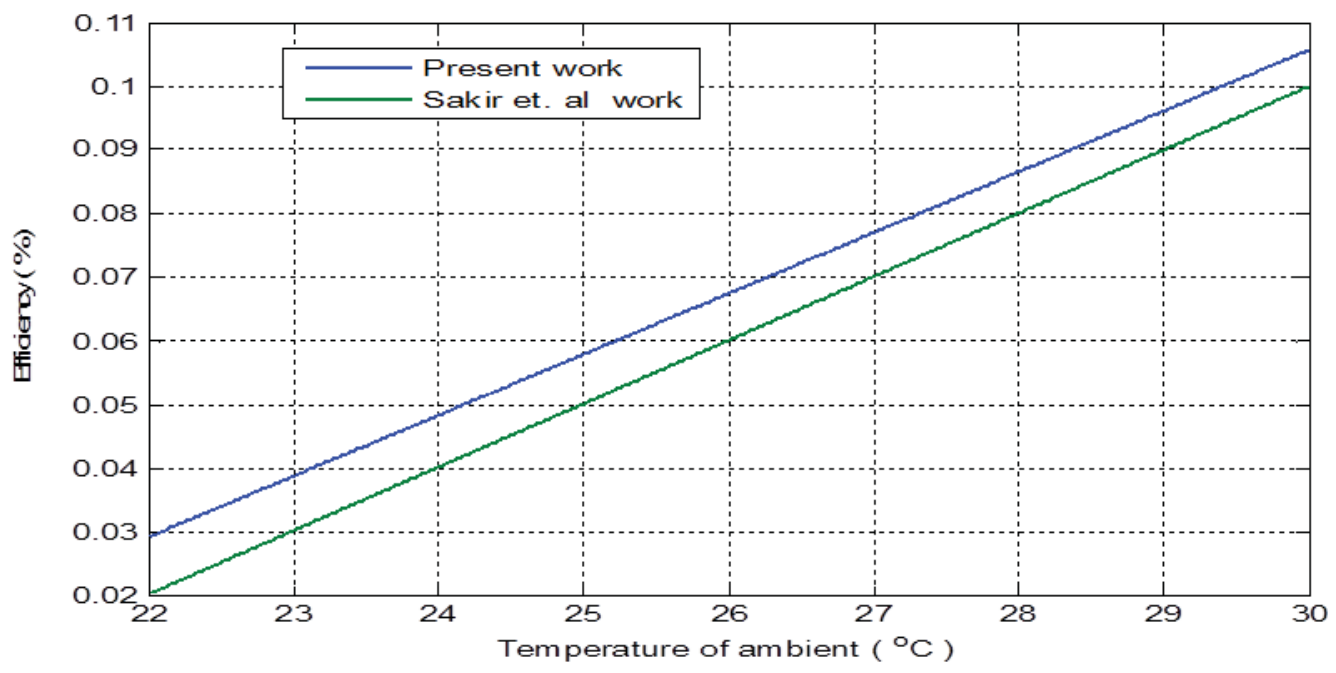

Fig. (20) Comparison of present study efficiency with previous study [15] with the same ambient temperature
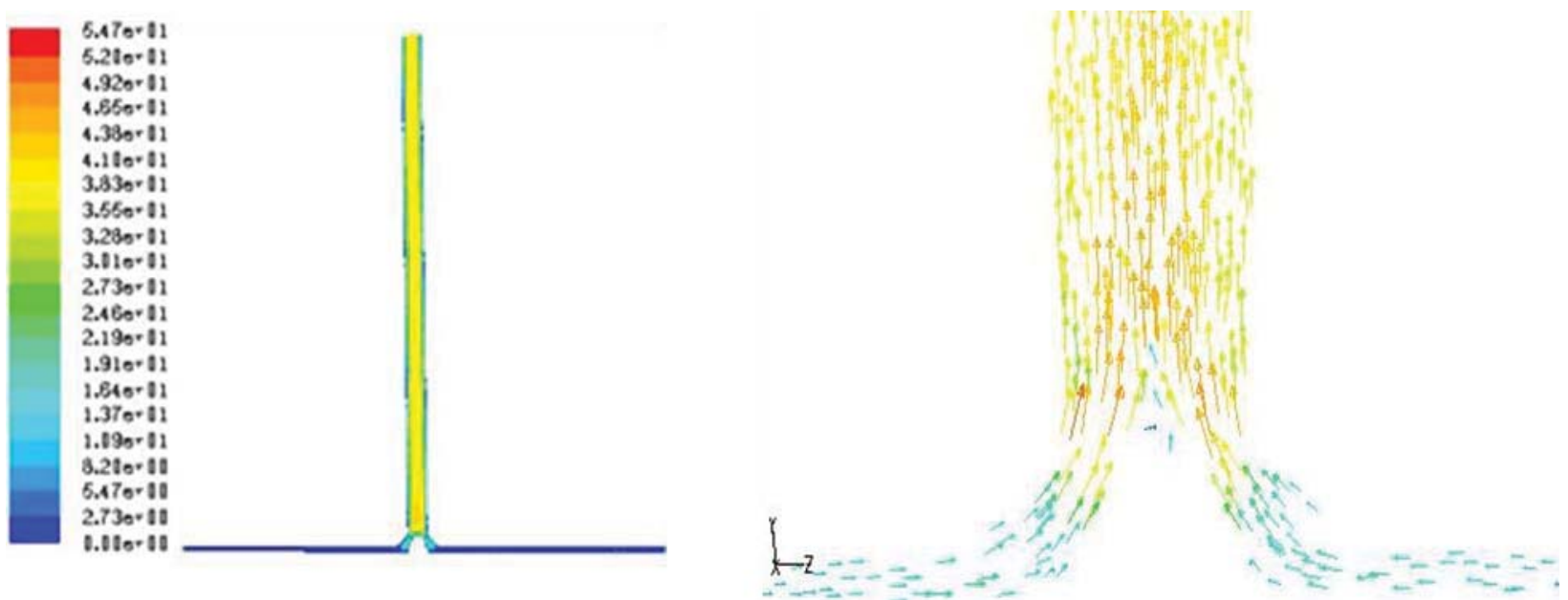

Fig. (21) Velocity magnitude for solar flux $\left(800 \mathrm{~W} / \mathrm{m}^{2}\right)$ 


\section{References}

1. Haaf W., Friedrich K., Mayr G. and Schlaich J., "Solar Chimneys, Part I: Principle and Construction of the Pilot Plant in Manzanares", Int. J. Sol .Energy, 2, 3-20, 1983.

2. J. Schlaich, "The Solar Chimney: Electricity from the Sun", Edition Axel Menges, Stuttgart, 1995.

3. N. Pasumarthi and S. A. Sherif, "Experimental and theoretical performance of a demonstration solar chimney model - Part I: Mathematical model development", International Journal of Energy Research, Volume 22, Issue 3, p.p. (277-288), 1998.

4. A. Koonsrisuk and T. Chitsomboon, " Dynamic similarity in solar chimney modelling", Solar Energy, Volume81, Issue 12, p.p.(1439-1446), 2007.

5. Y. J. Dai, H.B. Huang and R.Z. Wang, " Case study of solar chimney power plants in Northwestern regions of China”, Renewable Energy, Volume 28,p.p. (1295-1304), 2003.

6. J. Schlaich, R. Bergermann, W. Schiel and G. Weinrebe," Design of commercial solar tower systems - Utilization of solar induced convective flows for power generation", Journal of Solar Energy Engineering, Volume 127,p.p.(117-124), 2003.

7. M. Tingzhen, L. Wei and X. Guoliang, “Analytical and numerical investigation of the solar chimney power plant systems", International Journal of Energy Research, Volume30,Issue 11,p.p.(861-873), 2006.

8. G. Xu, T. Ming, Y. Pan, F. Meng and C. Zhou, "Numerical analysis on the performance of solar chimney power plant system”, Energy Conversion and Management, Volume 52, no 2, p.p.( 876-883), 2011.

9. S. K. Patel, D. Prasad and M. R. Ahmed." Computational studies on the effect of geometric parameters on the performance of a solar chimney power plant". Energy Conversion and Management .Volume77, p.p.( 424-431), 2014.

10. D. Annaratone, “Engineering Heat Transfer”, New York: Springer, 2010.

11. E. Bilgenand J. Rheault, "Solar chimney power plants for high latitudes", Solar Energy ,Volume 79,Issue 5,p.p.( 449-458), 2005.

12. X. P. Zhou, J. K.Yang, B.Xiao, G. Z.Hou, , \&X. Y. Shi,"Special climate around a Commercial Solar Chimney Power Plant", Journal of Engineering Energy, Volume134,Issue 1, p.p.(6-14), 2008.

13. Y. J. Dai, H.B. Huang and R.Z. Wang, " Case study of solar chimney power plants in Northwestern regions of China", Renewable Energy, Volume 28,p.p. (1295-1304), 2003. 
14. J. Schlaich, R. Bergermann, W. Schiel and G. Weinrebe," Design of commercial solar tower systems - Utilization of solar induced convective flows for power generation", Journal of Solar Energy Engineering, Volume 127,p.p.(117-124), 2003.

15. T. Sakir, B. K. Piash and S. Akhter,'Design, Construction and Performance Test of a Small Solar Chimney Power Plant”. Global Journals Inc. (USA), Volume 14, Issue 1, Version 1.0, 2014.

\section{Nomenclature;}

$\mathrm{A}_{\mathrm{C}}=$ the area of solar collector $\left(\mathrm{m}^{2}\right)$.

$\mathrm{A}_{\mathrm{Ch}}=$ the area of solar chimney $\left(\mathrm{m}^{2}\right)$.

$\mathrm{g}=$ Acceleration of gravity $\left(\mathrm{m} / \mathrm{s}^{2}\right)$.

$\mathrm{h}_{\text {inlet to coll. }}=$ the height of inlet solar collector $(\mathrm{m})$.

$\mathrm{H}_{\mathrm{Ch}}=$ the height of chimney (m).

$\mathrm{I}=$ incident solar radiation $\left(\mathrm{W} / \mathrm{m}^{2}\right)$.

$\mathrm{m}_{\mathrm{Ch}}^{\mathrm{o}}=$ The mass flow rate of air inlet chimney $(\mathrm{kg} / \mathrm{s})$.

$\mathrm{P}=$ power output of solar chimney power plant (Watt).

$\mathrm{T}_{\mathrm{amb}}=$ the temperature of ambient $\left({ }^{\circ} \mathrm{C}\right)$.

$\mathrm{V}_{\text {wind }}=$ the velocity of wind $(\mathrm{m} / \mathrm{s})$.

$\mathrm{U}=$ velocity of air inlet to chimney $(\mathrm{m} / \mathrm{s})$.

\section{Greek Symbols:}

$\tau=$ the transmittance of solar collector.

$\rho_{\mathrm{a}}=$ density of air ambient $\left(\mathrm{kg} / \mathrm{m}^{3}\right)$.

$\rho_{\text {e.c }}=$ density of air exit from solar collector $\left(\mathrm{kg} / \mathrm{m}^{3}\right)$.

$\Delta \mathrm{P}_{\text {ch. }}=$ pressure developed in chimney $(\mathrm{Pa})$. 